Article

\title{
Wheat Developmental Traits as Affected by the Interaction between Eps-7D and Temperature under Contrasting Photoperiods with Insensitive Ppd-D1 Background
}

\author{
Priyanka A. Basavaraddi ${ }^{1}$, Roxana Savin ${ }^{1}\left(\mathbb{D}\right.$, Stefano Bencivenga ${ }^{2}$, Simon Griffiths ${ }^{2}$ and Gustavo A. Slafer ${ }^{1,3, *(\mathbb{D})}$ \\ 1 Department of Crop and Forest Sciences-AGROTECNIO CERCA Center, University of Lleida, Av. R. Roure 191, \\ 25198 Lleida, Spain; priyanka.basavaraddi@udl.cat (P.A.B.); roxana.savin@udl.cat (R.S.) \\ 2 John Innes Centre, Norwich Research Park, Colney Ln, Norwich NR4 7UH, UK; \\ stefano.bencivenga@gmail.com (S.B.); simon.griffiths@jic.ac.uk (S.G.) \\ 3 ICREA, Catalonian Institution for Research and Advanced Studies, 23, 08010 Barcelona, Spain \\ * Correspondence: gustavo.slafer@udl.cat
}

check for updates

Citation: Basavaraddi, P.A.; Savin, R.; Bencivenga, S.; Griffiths, S.; Slafer, G.A. Wheat Developmental Traits as Affected by the Interaction between Eps-7D and Temperature under Contrasting Photoperiods with Insensitive Ppd-D1 Background. Plants 2021, 10, 547. https://doi.org/ $10.3390 /$ plants10030547

Academic Editor: Sibin Yu

Received: 30 January 2021

Accepted: 9 March 2021

Published: 13 March 2021

Publisher's Note: MDPI stays neutral with regard to jurisdictional claims in published maps and institutional affiliations.

Copyright: (c) 2021 by the authors. Licensee MDPI, Basel, Switzerland. This article is an open access article distributed under the terms and conditions of the Creative Commons Attribution (CC BY) license (https:/ / creativecommons.org/licenses/by/ $4.0 /)$.

\begin{abstract}
Earliness per se (Eps) genes are important to fine tune adaptation, and studying their probable pleiotropic effect on wheat yield traits is worthwhile. In addition, it has been shown that some Eps genes interact with temperature and therefore determining the likely Eps $\times$ temperature interaction is needed for each newly identified Eps gene. We studied two NILs differing in the newly identified Eps-7D (carrying insensitive Ppd-D1 in the background) under three temperature regimes $\left(9,15\right.$ and $18{ }^{\circ} \mathrm{C}$ ) and two photoperiods (12 and $\left.24 \mathrm{~h}\right)$. Eps-7D affected time to anthesis as expected and the Eps-7D-late allele extended both the period before and after terminal spikelet. The interaction effect of Eps-7D $\times$ temperature was significant but not cross-over: the magnitude and level of significance of the difference between NILs with the late or early allele was affected by the growing temperature (i.e., difference was least at $18^{\circ} \mathrm{C}$ and largest at $9{ }^{\circ} \mathrm{C}$ ), and the differences caused due to temperature sensitivity were influenced by photoperiod. The rate of leaf initiation was faster in NIL with Eps-7D-early than with the late allele which compensated for the shorter duration of leaf initiation resulting in similar final leaf number between two NILs. Eps-7D-late consistently increased spike fertility through improving floret primordia survival as a consequence of extending the late reproductive phase.
\end{abstract}

Keywords: spike fertility; leaf appearance; spikelet primordia; temperature $\times$ photoperiod

\section{Introduction}

Wheat development is critical for yield determination as it controls not only adaptation (i.e., the critical stage of anthesis must occur when conditions are best, minimising stresses during grain number determination and grain weight realisation [1,2]) but also the timing and rate of generation of structures that will become sources and sinks [3,4]. Indeed, wheat yield (as well as that of other grain crops) is the consequence of the balance between source- and sink-strength, in turn determined as the result of initiation, degeneration and rate of growth of leaves, tillers, spikelets, florets and grains. Therefore, genetic factors controlling the duration of the developmental phases would be expected to have pleiotropic effect on yield traits [5,6]. Certainly, a number of studies have shown that modifying the duration of particular developmental phases through genetic factors [7-11] or environmental factors [4,12-16] could produce parallel changes in spike fertility which, in turn, is a major determinant of wheat yield $[17,18]$.

Time to anthesis in wheat encompasses various phases with different degrees of sensitivities towards cold temperature and daylength termed as vernalisation (Vrn) and photoperiod $(P p d)$ sensitivities, respectively. The genetic factors responsible for such sensitivities are referred as Vrn and Ppd genes. The Vrn-sensitivity genes define the growth 
habit (Vrn-sensitive cultivars are winter wheats while Vrn-insensitive cultivars are spring wheats), while $P p d$-sensitivity genes determine whether flowering will be earlier (cultivars with little or no sensitivity) or later (sensitive cultivars). However, once the effects of Vrn and $P p d$ sensitivity genes are removed (since genotypes have insensitive alleles for all these genes or because plants are gown under long days after having been fully vernalised), genotypes may still exhibit differences in flowering time. These genotypic differences are known as earliness per se (Eps) or intrinsic earliness [19]. Past wheat breeding has largely optimised time to anthesis to expand adaptation and to maximise yield by positioning anthesis time avoiding yield penalties due to abiotic stresses $[20,21]$. Then, major changes in anthesis time may not be as relevant as fine adjustments, at least in traditional wheat growing regions where the crop has been bred and grown for a long period. The importance of Eps genes may be even higher than that of the major Vrn and Ppd sensitivity genes when the need is to fine adjust phenology because they normally have relatively small effects [8,22-24]. Indeed, due to their relatively subtle effect, Eps genes may have gone undetected during the course of selection [25], and are mostly identified as QTLs [25]. Although much lesser known, their possible pleotropic effect on yield components might be one of the reasons for their indirect selection [26].

Most of what is known about identified Eps genes relates to their effects on time to anthesis. The importance of these genetic factors, like any other genes, to be used in breeding programmes is limited by the lack of understanding of their detailed effect on individual phases occurring before anthesis, and their possible influence on different yield attributes along the way. Although yield components are being determined during the whole growing season, some phases are more critical than others $[27,28]$. Indeed, it is during the phase from terminal spikelet (TS) to anthesis (the late reproductive phase, LRP) when spike dry weight and spike fertility are determined [14,27,29,30].

Some recent studies have shown the possible relevance of Eps genes not only in fine adjusting anthesis time, but also through affecting spikelet number [26]. This is in line with the hypothesis that genes effecting developmental traits might alter the dynamics of organs initiated in response to changes in the duration [11,31-35]. The dynamics of organs such as tillers, spikelets and florets (resulting a posteriori in yield components) may well depend, at least in part, upon the time allocated for their development.

Despite Eps genes owe their name to the assumption that genotypic differences produced were "intrinsic" (per se) and, therefore, independent of the environment [19], it was hypothesised to be sensitive to temperature [36]. The speculated Eps $\times$ temperature interaction [8,22,37], was recently proven in few studies (e.g., [38,39]). Furthermore, what we collectively call Eps genes are consistent in their effect on time to anthesis, but could strongly differ in their effects on other traits. It could be possible that the temperature responses of each Eps be different in terms of type and magnitude of the response and this needs to be studied for each particular Eps gene that could be of interest for breeding. Understanding whether temperature affects the functionality of each Eps is necessary to explore the kind of environment in which those Eps genes could be effective and beneficial.

Recently an Eps QTL on chromosome 7D was identified in wheat which was known to influence time to heading [40]. Four NILs were generated from the cross Paragon (a modern UK commercial cultivar [41] and Baj (a CIMMYT cultivar, used frequently as check [42], both of which are spring type with no requirements of vernalisation. Paragon has the Eps7D-late and Ppd-D1b (photoperiod-sensitive) alleles while Baj has the Eps-7D-early and PpdD1a (photoperiod-insensitive) alleles. Thus, the four NILs comprised the four combinations of both alleles and had identical mixture of Paragon and Baj in the background. For simplicity, in the present paper we aimed to evaluate the direct effect of the Eps-7D alleles (comparing the performance of the NILs having always the photoperiod-insensitive Ppd-D1a allele) and their interaction with temperature at two contrasting photoperiods, quantifying the effects not only on phenology but also on dynamics of organ development. The NILs were grown under three constant temperatures $\left(9,15\right.$ and $\left.18^{\circ} \mathrm{C}\right)$ and two very contrasting photoperiods (12 and $24 \mathrm{~h}$ ). In a companion paper [43], we focused on the Eps-7D $\times$ Ppd-D1 interaction, 
analysing to what degree the allelic status of the Eps-7D locus affects the sensitivity to photoperiod given by $P p d-D 1 b$ and its interaction with temperature and vice-versa (whether the allelic form of $P p d-D 1$ modifies the effect of $E p s-7 D$ and its interaction with temperature).

\section{Results}

Time to anthesis was inversely related to both growing temperature (longest at $9{ }^{\circ} \mathrm{C}$ and shortest at $18{ }^{\circ} \mathrm{C}$ ) and photoperiod (longest at $12 \mathrm{~h}$ and shortest at $24 \mathrm{~h}$ ) (Figure 1), the latter even though all lines carry the insensitive photoperiod allele in chromosome 1D (Ppd-D1a). Although these two direct effects of temperature and photoperiod are expected we also found a significant interaction between them (Figure 1C), that was not simply a reflection of the temperature effect on development as the difference between short and long photoperiod was largest in the intermediate temperature: averaging across the two Eps alleles the difference in duration to anthesis between short and long photoperiod was ca. 23, 35 and 24 days at 18,15 and $9^{\circ} \mathrm{C}$, respectively; cf. Figure 1A,B).
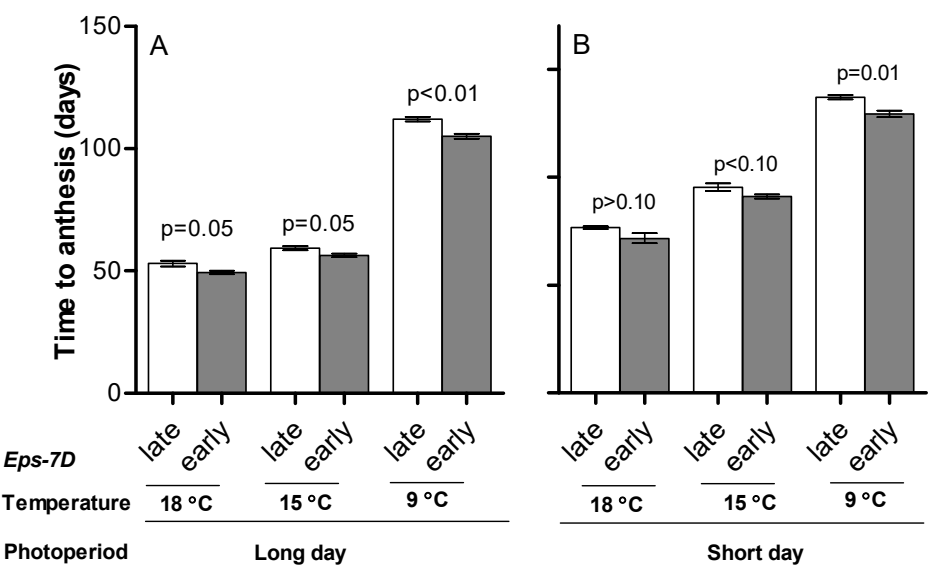

\begin{tabular}{|c|c|}
\hline Source of variation & $\begin{array}{c}\text { Time to } \\
\text { anthesis }\end{array}$ \\
\hline Temperature & $22412.67^{* * *}$ \\
\hline Photoperiod & $6889.00^{* * *}$ \\
\hline TemperaturexPhotoperiod & $268.67^{* * *}$ \\
\hline Eps-7D & $235.11^{* * *}$ \\
\hline Temperature×Eps-7D & $22.89^{*}$ \\
\hline Photoperiod×Eps-7D & $2.78^{\mathrm{NS}}$ \\
\hline Temperature×Photoperiod×Eps-7D & $0.22^{\mathrm{NS}}$ \\
\hline
\end{tabular}

Figure 1. Duration of whole phase from seedling emergence to anthesis for the lines carrying Eps-7D-late (open bars) or -early (closed bars) on Ppd-D1a background under three growing temperatures under long (A) and short days (B). Error bars indicate the standard error of the means (SEMs) and the " $p$ " values stand for the level of significance exclusively due to the action of the Eps-7D gene within each temperature and photoperiod condition. The output (mean squares) of the three-way ANOVA for time to anthesis (days) is included on the right (C). Significance level ${ }^{*} p<0.05 ;{ }^{* *} p<0.001$; NS = non-significant.

More importantly, regarding our main objective, there was a significant interaction between the effect of the Eps-7D alleles on time to anthesis and the growing temperature, and that interaction was consistently seen across the two contrasting photoperiods (Figure $1 \mathrm{~A}, \mathrm{~B})$, as the interaction $E p s-7 D \times$ photoperiod and the triple interaction $($ Eps-7D $\times$ temperature $\times$ photoperiod) were not significant (Figure $1 C)$. However, the Eps-7D $\times$ temperature interaction was significant but not cross-over: the NIL with the Eps-7D-late allele was always later to flower than that with the early allele (Figure 1), although the magnitude and level of significance of the difference between NILs with the late or early allele was affected by the growing temperature (i.e., difference was least, and non-significant under SD, at $18^{\circ} \mathrm{C}$ and largest and clearly significant at $9^{\circ} \mathrm{C}$; Figure $1 \mathrm{~A}, \mathrm{~B}$ ).

The effects of temperature and photoperiod on time to anthesis were also seen for the two component phases considered here: both time from seedling emergence to TS (when all leaves and spikelets are initiated) and from then to anthesis (i.e., the late reproductive phase of stem elongation, LRP, when florets are firstly initiated and then a proportion of them die) were longer under low temperatures and short photoperiod than under warm temperatures and long photoperiod (Figure 2). Even though both phases were clearly sensitive to the growing temperature, their sensitivity was not the same: duration from seedling emergence to TS responded to temperature less markedly than duration of the LRP (cf. differences between Figure 2A,B with Figure 2C,D, taking into account the different scales). 

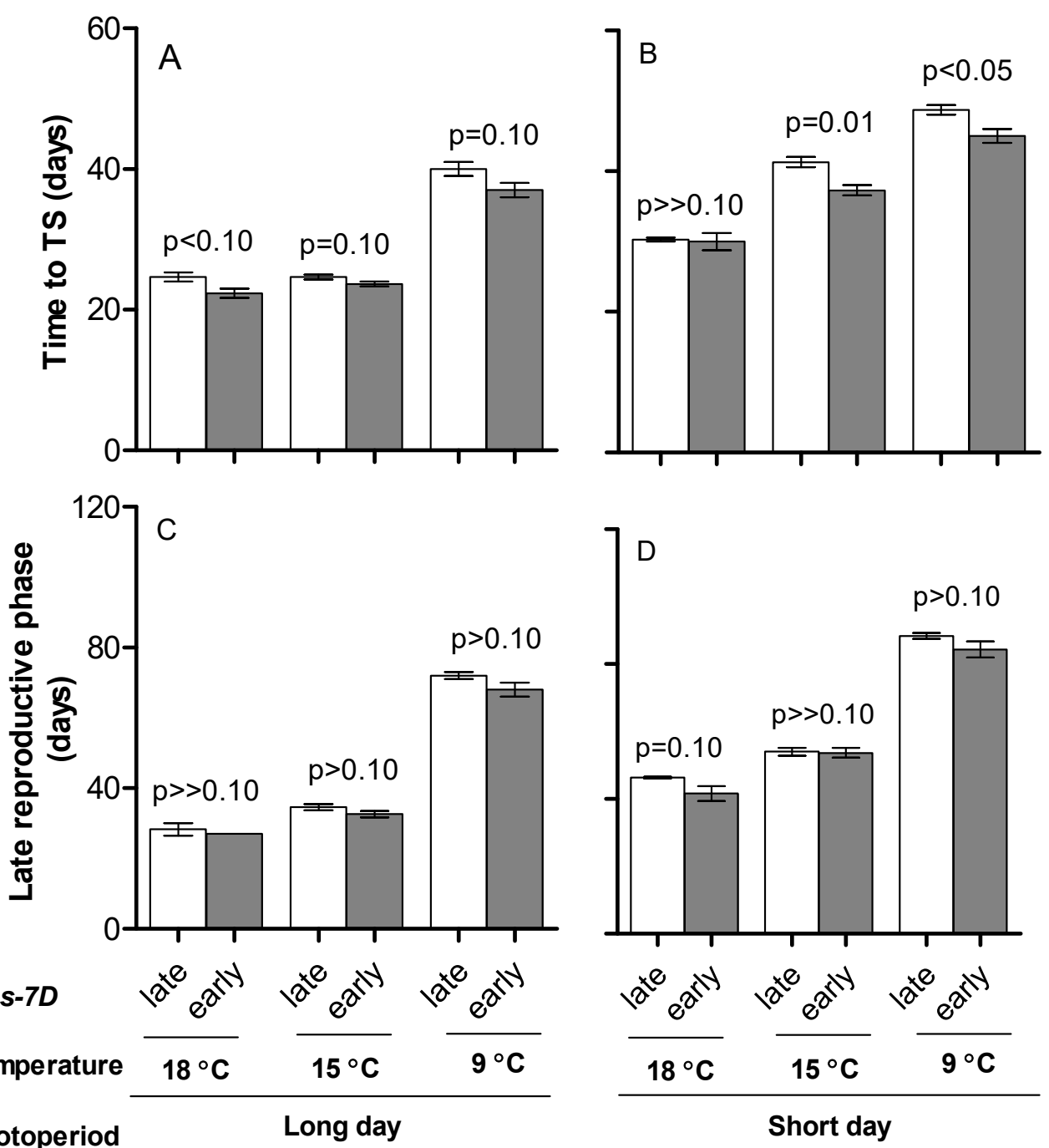

Photoperiod

Long day

Figure 2. Duration of phase from seedling emergence to TS $(\mathbf{A}, \mathbf{B})$ and time from then to anthesis, late reproductive phase (C,D) for the lines carrying Eps-7D-late (open bars) or early (closed bar) on $P p d-D 1 a$ background under long $(\mathbf{A}, \mathbf{C})$ and short days $(\mathbf{B}, \mathbf{D})$ at three temperatures. Error bars indicate the SEMs and the " $p$ " values stand for the level of significance exclusively due to the action of the Eps-7D gene within each temperature and photoperiod condition.

Regarding the specific effect of the Eps-7D gene, the NIL with the Eps-7D-late allele tended to have longer phases both from seedling emergence to TS and from then to anthesis across all growing conditions (Figure 2). However, as the effect on the whole period from seedling emergence to anthesis was subtle, that on the duration of each of its component phases was naturally even smaller and most differences became non-significant with the two-way ANOVA analyses done for each growing condition; particularly for the LRP (Figure 2). However, when looking at the relationship between the duration of the total time to anthesis and its component phases it seems clear that both were at least equally important, not only reflecting the differences between growing conditions but also the effects of the Eps-7D gene (Supplementary Figure S1). Thus, even though most differences between NILs with Eps-7D-early and -late alleles were non-significant for the LRP (Figure 2C,D), it can be seen that the magnitude of the shortening of the phases produced by the effect of having the Eps-7D-early allele was similar in relative terms for both phases (averaging across the six growing conditions the duration of the phase from seedling emergence to TS and that of the LRP was 2.5 and $3 \mathrm{~d}$ earlier, respectively, in the NIL with the Eps-7D-early than with the -late allele). 
Final leaf number was not significantly affected by temperature or the Eps-7D gene (Table 1). Thus, any effects of these two factors on the duration of the vegetative phase of leaf initiation (virtually from sowing to seedling emergence or soon after it; see below) would have been compensated by opposite effects on the rate of leaf initiation.

Table 1. Effects of the Eps-7D gene on final leaf number (FLN), rate of leaf appearance (RLA; estimated as the slope of the linear regression of leaf number vs. thermal time), and the coefficient of determination for that regression $\left(\mathrm{r}^{2}\right)$, when grown under two contrasting photoperiods (12 and $\left.24 \mathrm{~h}\right)$ and three temperatures.

\begin{tabular}{|c|c|c|c|c|c|}
\hline \multicolumn{2}{|c|}{ Growing Conditions } & $\begin{array}{l}\text { Allele at } \\
\text { Eps-7D }\end{array}$ & FLN & $\begin{array}{c}\text { RLA } \\
\left({\left.\text { Leaves } d^{-1}\right)}^{-1}\right.\end{array}$ & $\mathbf{r}^{2}$ \\
\hline \multirow{6}{*}{ Long day } & \multirow[b]{2}{*}{$18^{\circ} \mathrm{C}$} & Late & $6.2 \pm 0.1$ & $0.142 \pm 0.003$ & $0.953 * * *$ \\
\hline & & Early & $6.0 \pm 0.0$ & $0.149 \pm 0.005$ & $0.923^{* * *}$ \\
\hline & \multirow{2}{*}{$15^{\circ} \mathrm{C}$} & Late & $6.0 \pm 0.0$ & $0.122 \pm 0.001$ & $0.986^{* * *}$ \\
\hline & & Early & $6.0 \pm 0.0$ & $0.131 \pm 0.001$ & $0.983^{* * *}$ \\
\hline & \multirow{2}{*}{$9{ }^{\circ} \mathrm{C}$} & Late & $6.0 \pm 0.0$ & $0.083 \pm 0.001$ & $0.980^{* * *}$ \\
\hline & & Early & $6.0 \pm 0.0$ & $0.083 \pm 0.001$ & $0.968^{* * *}$ \\
\hline \multirow{6}{*}{ Short day } & \multirow{2}{*}{$18^{\circ} \mathrm{C}$} & Late & $7.0 \pm 0.0$ & $0.126 \pm 0.001$ & $0.983^{* * *}$ \\
\hline & & Early & $6.6 \pm 0.1$ & $0.130 \pm 0.002$ & $0.975 * * *$ \\
\hline & \multirow{2}{*}{$15^{\circ} \mathrm{C}$} & Late & $7.0 \pm 0.0$ & $0.083 \pm 0.001$ & $0.985^{* * *}$ \\
\hline & & Early & $6.9 \pm 0.1$ & $0.087 \pm 0.001$ & $0.984^{* * *}$ \\
\hline & \multirow{2}{*}{$9^{\circ} \mathrm{C}$} & Late & $6.7 \pm 0.2$ & $0.066 \pm 0.001$ & $0.959^{* * *}$ \\
\hline & & Early & $6.1 \pm 0.1$ & $0.072 \pm 0.001$ & $0.977^{* * *}$ \\
\hline
\end{tabular}

$\overline{* * *}$ All linear regressions of leaf number vs. time after seedling emergence were highly significant $(p<0.001$; $\mathrm{n}=10-25$, depending on the temperatures and photoperiod as leaf number was determined thrice a week).

Photoperiod effect on FLN was small but clear; averaging across temperatures and Eps-7D alleles plants developed slightly less than one additional leaf if grown under short photoperiod. This means that when plants were exposed to long days, they immediately reached floral initiation at seedling emergence (as there would be four leaf primordia in the embryo and ca. two leaf primordia would have been initiated between sowing and seedling emergence) whilst at short days it took an additional plastochron to reach floral initiation, a difference that was very slight as expected (as these lines were both insensitive to photoperiod regarding the major gene $P p d-D 1)$.

The initiated leaves always appeared at a reasonably constant pace (as indicated by the very high coefficients of determination of the linear relationship between leaf number and time; $\mathrm{r}^{2}>0.92, \mathrm{n} \geq 10$; Table 1 ). The rate of appearance of these leaves was positively affected by temperature and photoperiod (the higher the temperature or longer the day the faster the rate of leaf appearance; Table 1). The Eps-7D gene also affected slightly but consistently the rate of leaf appearance, appearing faster in NIL with the Eps-7D-early allele than the one with late allele, with the exception of plants grown under long days and $9{ }^{\circ} \mathrm{C}$ in which the rates of leaf appearance of the NILs did not differ (Table 1).

As floral initiation occurred at seedling emergence or just one plastochron later (see above), we could only collect data revealing the dynamics of spikelet initiation (and estimate from that dynamics the spikelet plastochron). Spikelets were initiated at a more or less constant rate whose actual value was rather similar (and few differences were not consistent) for NILs with the early or late allele in Eps-7D, and in all cases clearly slower at 9 than at 15 or $18{ }^{\circ} \mathrm{C}$ and slower under short than under long days (Figure 3).

The dynamics of floret development was recorded for all the initiated florets that reached a developmental stage of W4.5 within spikelets until they either reached W10 (fertile floret) or died. Floret 1 (most proximal floret to the rachis) in both Eps-7D-late and -early lines reached the stage of fertile floret (W10) under all three temperatures and two photoperiods, while F4 (the most distal floret consistently reaching at least the stage W4.5) has never developed to a stage close to W10 in any of the growing conditions (Supplementary Figure S2). Then to understand the effects of treatments on spike fertility, we concentrated the results on the fate of the second and third florets from the rachis (F2 
and F3, respectively) which were those responsible for the differences in number of fertile florets per spike at anthesis.

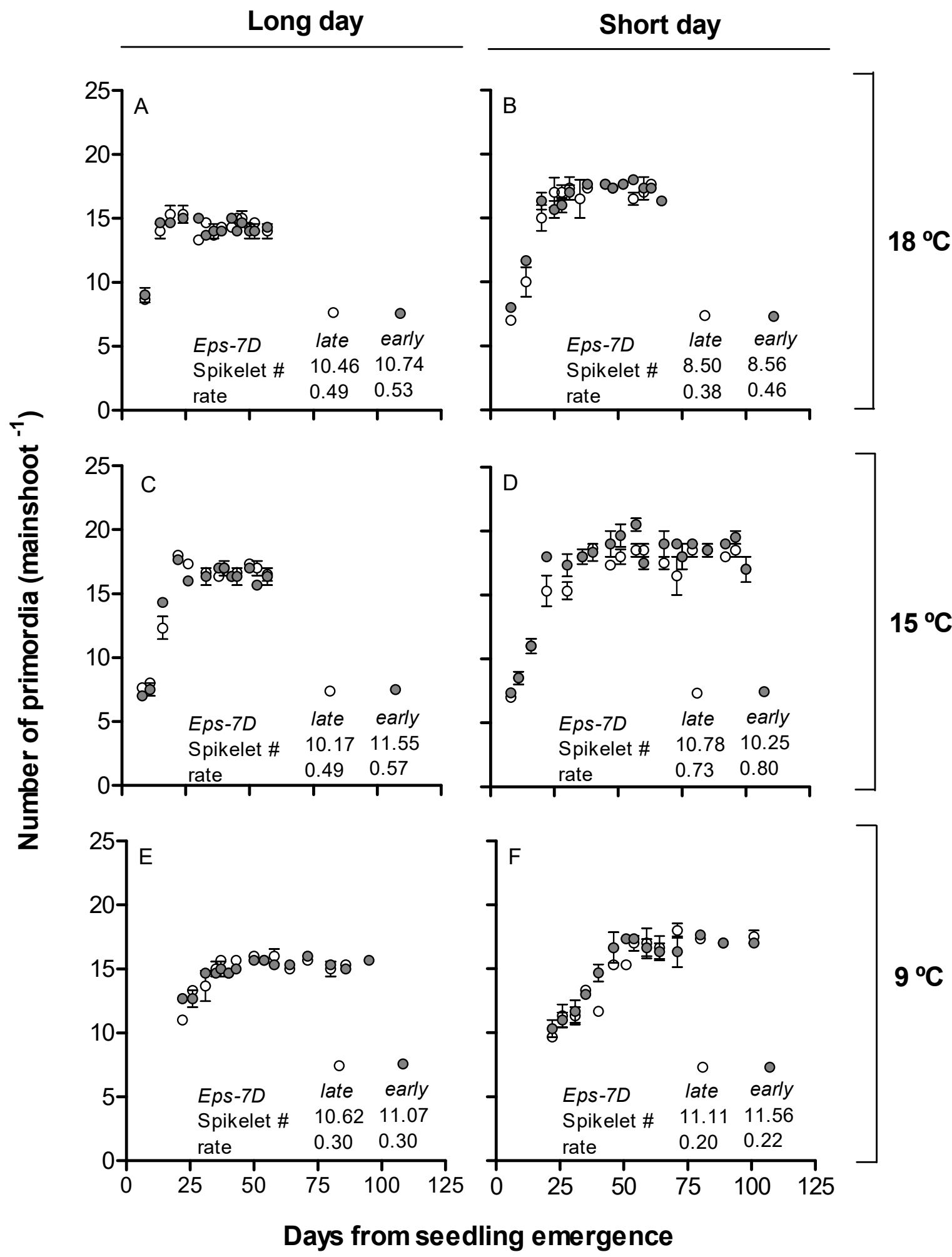

Figure 3. Relationship between number of primordia and days from seedling emergence for Eps-7D-late (open circles) and early (closed circles) under long $(\mathbf{A}, \mathbf{C}, \mathbf{E})$ and short days $(\mathbf{B}, \mathbf{D}, \mathbf{F})$ at $18(\mathbf{A}, \mathbf{B}), 15(\mathbf{C}, \mathbf{D})$ and $9{ }^{\circ} \mathbf{C}(\mathbf{E}, \mathbf{F})$. Inside each panel are the total number of spikelet primordia and rate of spikelet initiation (spikelets day ${ }^{-1}$ ). 
Similar to the situation for the initiation of spikelets, the rates of floret development were affected by the growing conditions. Florets developed much faster at 18 than at $9{ }^{\circ} \mathrm{C}$ but also the opposite was true with the duration of the period of floret development: shortest and longest at 18 and $9{ }^{\circ} \mathrm{C}$, respectively (Figure 4 and Supplementary Figure S2). Photoperiod did not affect noticeably the rate but did modify the duration of floret development (Figure 4 and Supplementary Figure S2).

Floret 2

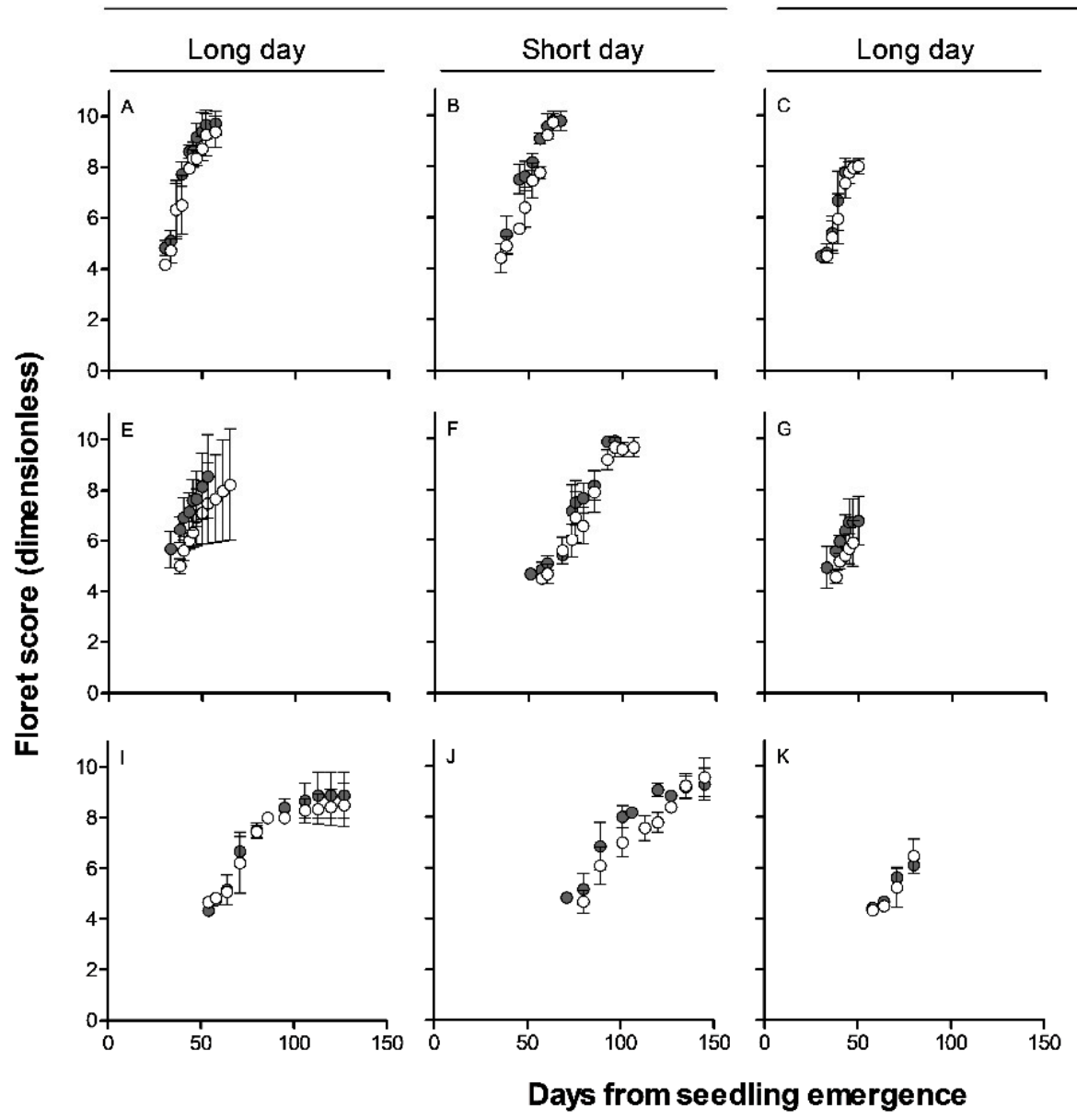

Floret 3

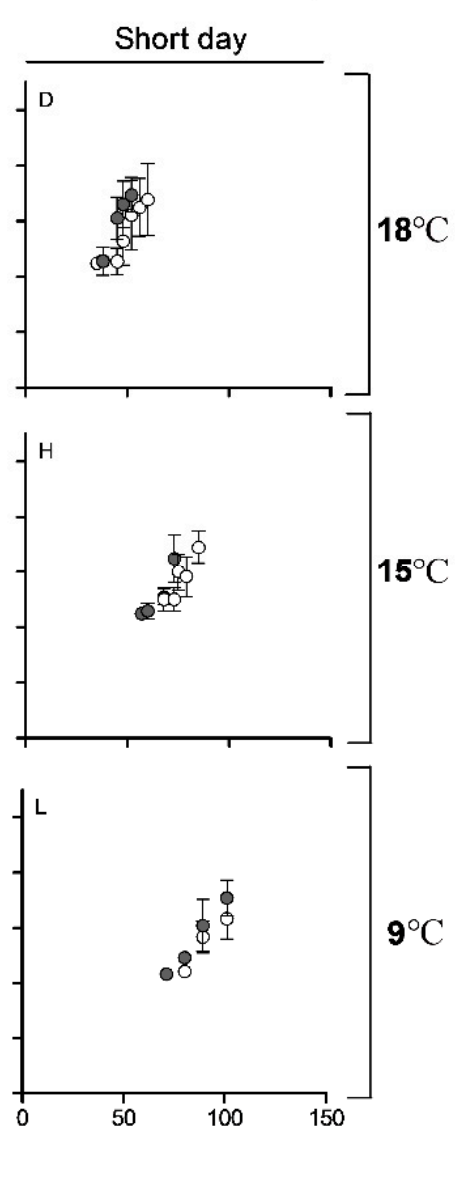

Figure 4. Relationship between floret development (floret score, scale proposed by Waddington et al. [44]) and days from seedling emergence for Eps-7D-late (open circles) and early (closed circles) for floret 2 (A,B,E,F,I,J) and floret 3 (C,D,G,H,K,L) under long and short days at $18(\mathbf{A}-\mathbf{D}), 15(\mathbf{E}-\mathbf{H})$ and $9{ }^{\circ} \mathrm{C}(\mathbf{I}-\mathbf{L})$. The error bars are the standard error of means, considering the means of floret scores from apical, central and basal spikelets.

Regarding the effect of the Eps-7D gene, Floret 2 was initiated more or less at the same time for both Eps-7D-late and -early under long day in all the three temperatures but under short day Eps-7D-early tended to initiate the F2 earlier and had faster development compared to the effect of the late allele (Figure 4).

Under long day $\mathrm{F} 2$ reached $\mathrm{W} 10$ at $18^{\circ} \mathrm{C}$ for both Eps-7D-late and -early alleles. Under lower temperatures $\left(15\right.$ and $\left.9{ }^{\circ} \mathrm{C}\right) \mathrm{F} 2$ florets in one third of the sampled plants reached W10 in lines with Eps-7D-late allele while all F2 aborted in Eps-7D-early lines. None of the F3 florets reached W10 regardless of whether the lines had the Eps-7D-late or -early alleles and therefore the effect of the Eps-7D gene on fertile florets per spike was inappreciable (Figure 4). Even though the F3 and F4 florets did never reach the stage of fertile florets they attained higher floret score when the line had the Eps-7D-late allele, especially under short day conditions (Figure 4 and Supplementary Figure S2). 
Spike fertility was not consistently affected by temperature (because of the opposite effects of this factor in the rate and duration of floret development, see above); and was higher in short than in long days by virtue of the photoperiod effect on duration of floret development (Figure 5).

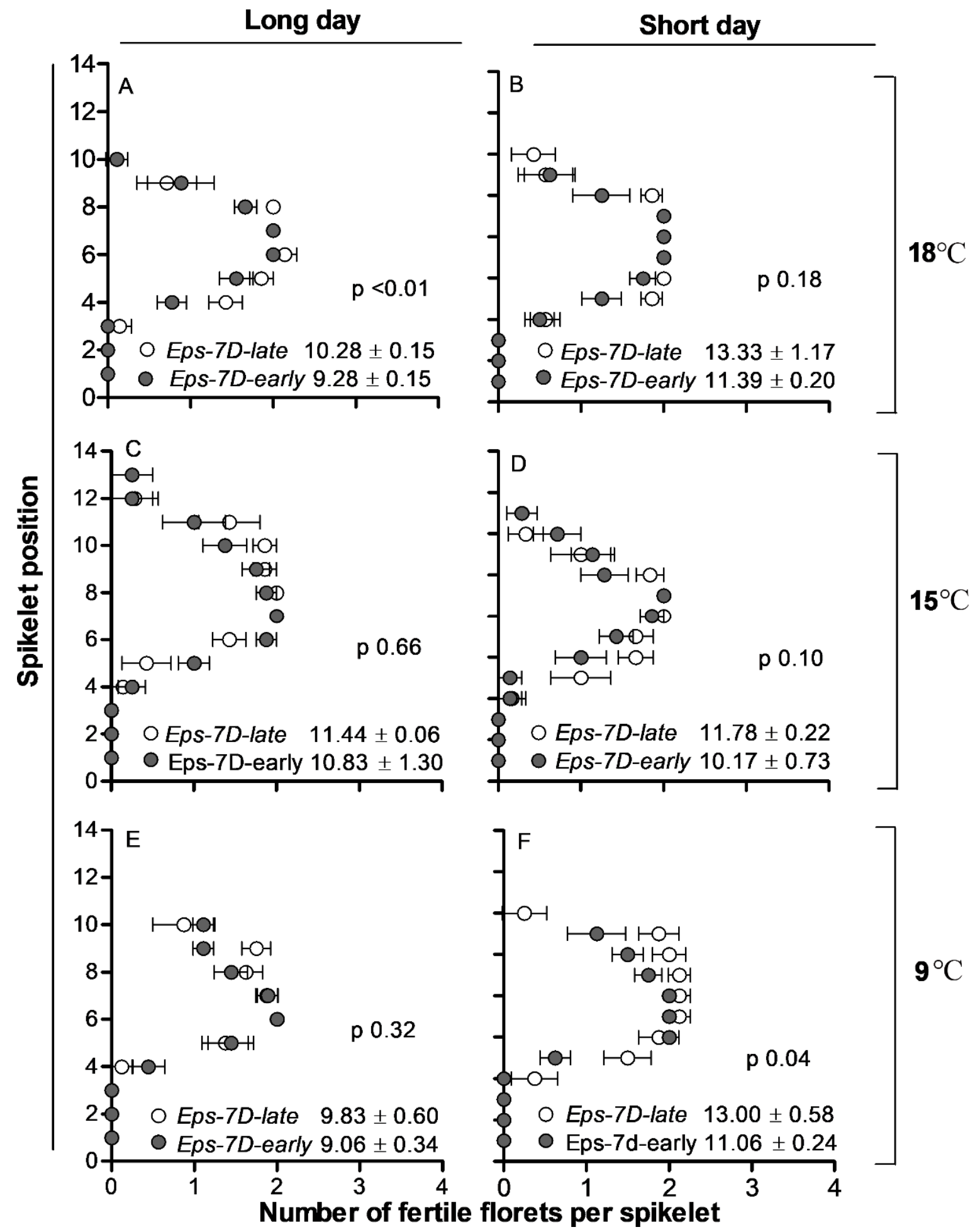

Figure 5. Number of fertile florets at anthesis per spikelet from basal to terminal spikelet for Eps-7D-late (open circles) and -early (closed circles) NILs under long (A,C,E) and shot days (B,D,F) at $18(\mathbf{A}, \mathbf{B}), 15(\mathbf{C}, \mathbf{D})$ and $9{ }^{\circ} \mathrm{C}(\mathbf{E}, \mathbf{F})$. Inside each panel are the fertile florets per spike with standard error of means and $p$ value. 
The Eps-7D gene had an effect on the number of fertile florets per spike as the NIL with the late allele showed a consistent trend (though not always statistically significant) to have more fertile florets than the NIL with the early allele (Figure 5).

The overall direct effect of Eps-7D gene on the number of fertile florets was much higher than the direct effect of temperature and Eps-7D $\times$ temperature interaction effect $(\mathrm{F}$ ratio was 8.50, 5.61 and 0.65 for Eps-7D, temperature and their interaction, respectively). Averaging across temperatures the Eps-7D-late lines had almost ca. 1 extra fertile floret per spike than that of early allele under long day, and this difference doubled under short photoperiod (Figure 5).

\section{Discussion}

Although the main focus of this study was on the effects of this newly reported Eps-7D gene on developmental processes and whether or not those effects were affected by the growing temperature, we also reported the effects of temperature, photoperiod and their interaction on these developmental processes. As the temperature $\times$ photoperiod and Eps-7D $\times$ temperature interactions were significant (but that of Eps-7D $\times$ photoperiod and the triple interactions were not), we firstly discussed briefly the effects of the environmental factors and then those of the Eps gene and its interaction with temperature.

\subsection{Temperature, Photoperiod and Their Interaction}

In general, developmental rates were faster (reducing the length of both the whole cycle to anthesis and its component phases occurring before and after TS) under high than under low temperature conditions. This overall effect is in line with the recognised universal effect of temperature on accelerating developmental processes not only in wheat $[45,46]$ but also in other crops [47] and unrelated organisms [48]. Also the rate of leaf appearance (that was constant for all leaves, as expected when FLN is less than 8; [49,50]) was positively responsive to temperature; as has been known for a long time (e.g., [50,51]. As temperature accelerated the rate of primordia initiation, we found a sort of compensation with the acceleration of development (i.e., phases are shorter but primordia are initiated faster under higher temperatures). Consequently, no clear effects of temperature were evident for the FLN, the number of spikelets per spike or the number of fertile florets per spike, again as expected from this universal effect of temperature, affecting therefore similarly the rates of both phenological development and initiation of primordia during the corresponding phenological phases [45].

There was a direct effect of photoperiod on time to anthesis, that was not restricted to the phase from seedling emergence to TS as the LRP was also affected by the exposure to contrasting day lengths (in line with previous evidences in the literature showing that the LRP can be highly sensitive to photoperiod; $[10,13,32])$. As NILs had the insensitive allele for $P p d-D 1$ gene $(P p d-D 1 a)$, which is the insensitivity gene frequently reported to have the strongest effect (e.g., [10,52]), we did not expect large differences between growing the plants at short or long photoperiod. However, the NILs would have sensitive alleles in the Ppd-1 loci on the A and/or B genome. Indeed, we could not discard that a new Eps-2B could actually be $P p d-B 1$ [40]. These genes produce responses that are frequently less noticeable than Ppd-D1, but still significant [8,53-55]. Again, as expected from the literature, photoperiod effects on the rate of phenological development is not paralleled by concomitant effects on the rate of leaf initiation and, therefore, the final number of leaves was increased under short days [56]. Long photoperiod not only reduced FLN but also accelerated the rate of leaf appearance [50,57] both factors contributing to the shortening of the time to anthesis in response to long photoperiod.

Beyond the direct effects of temperature and photoperiod discussed above, in the present study there was a clear temperature $\times$ photoperiod interaction. For instance, analysing in detail the responses to temperature in the contrasting photoperiods there were particularities that are worth noticing. The length of the phase under long day were similar for 15 and $18{ }^{\circ} \mathrm{C}$ while it differed clearly under short day between these 
temperatures showing shorter phase at 18 than at $15{ }^{\circ} \mathrm{C}$ indicating that the probable $\mathrm{T}_{\text {optimum }}$ for development under long days is lower than that under short days. This was all the more so when looking at the time to TS but not so much when the LRP was considered, which is in line with the fact that cardinal temperatures would increase with the advance in development [58,59]. The fact that photoperiod affect the temperature response has been described several times not only for wheat $[60,61]$ but also for barley $[62,63]$.

\subsection{Eps-7D Effect and Eps-7D $\times$ Temperature Interaction}

In line with the previous knowledge about other known Eps genes [24,25,38], the Eps-7D studied here also had subtle, though consistent and significant, effects on time to anthesis. This is not surprising as even though each Eps gene would have different mechanisms of action, by definition they all result in relatively small differences in time to anthesis or heading $[23,25]$, and because they are subtle they may be undetectable if photoperiod and vernalisation requirements are not fully satisfied in sensitive genotypes [25]. There are very few studies on detailed effect of Eps genes on pre-anthesis and, unlike with the overall time to anthesis, they vary in their conclusion on whether Eps affect early or late stages of development. While the study by Lewis et al. [8] reported that the effect of Eps- $A^{m} l$ on time to anthesis was mainly due to its effect on the duration of early developmental phases until TS, others reported varying effect of Eps-D1 on all the three phases, vegetative, early reproductive and late reproductive phase [24]. The Eps-7D we characterised in the present study (with Ppd-D1a in the genetic background) was found to affect the duration of both early phase from seedling emergence to TS as well as that of the LRP, similarly to what was reported for the Eps-D1 before [24]. The effect of Eps-7D on time to anthesis was related to both number and rate of leaf appeared in that the NIL with Eps-7D-late allele had slightly more leaves developed that appeared slightly slower than the NIL with Eps-7D-early allele.

Considering that the NILs had similar FLN, it might seem like effect of Eps-7D on phenology was realised much later during the development (after flag leaf initiation). Indeed, apex dissection showed that Eps-7D affected development since early reproductive phase. The rate of leaf appearance was affected by Eps-7D allele which resulted in Eps-7Dearly allele to have similar FLN as that of late allele for a shorter duration. This implies a different mechanism regarding leaf development than what was shown for the EpsD1; which affected time to anthesis mainly by affecting time from flag leaf emergence to anthesis [39].

Improvements in spike fertility may be possible with either lengthening the LRP (with no compensation from the change in the rate of floret development, so that more florets may become fertile) and/or increasing spike dry weight at anthesis (which could be in turn the result of lengthened LRP or increased dry matter partitioning; Refs. [64,65]. Changes in spike dry weight are uncertain with minor differences in phenology (unless partitioning was altered) and differences in spike fertility would be very subtle which would mainly be the result of the efficiency with which resources are used to maintain floret development reducing the rate of floret death ([39] and references quoted there in). The consistent trend observed in the present study for the Eps-7D-late allele to produce more fertile florets per spike than the early allele was the result of two extra florets (F2 and F3 in this case) that continued developing for a slightly longer time as a consequence of the slightly lengthened LRP. Effect of Eps-7D on the duration of floret development did not alter number of floret primordia produced but altered floret survival which is strongly supported by other studies where major or minor differences in length of floret development phase resulting in differences in spike fertility was not through number of floret primordia produced ([39] and references quoted there in). There was a large difference in duration of floret development between 18 and $9{ }^{\circ} \mathrm{C}$ but this did not generate similar improvement in fertile florets per spike at the low temperature because the driving force for decelerating the rate of development during the LRP was also decelerating the rate of floret development. This compensation is expected when the differences in temperature 
do not explore ranges producing high temperature stress, when the reproductive output of crops is clearly impaired e.g., [66-68].

Further, in the present study there was clear interaction effect of $E p s-7 D \times$ temperature on phenology. The fact that temperature accelerates development of all phases in all crops only means that there would be no cases of insensitivity, but genotypic variation in sensitivity has been shown since long time ago $[36,69,70]$. At least in part, the genotypic variation in sensitivity to temperature might reflect the interaction of Eps genes with temperature [19]. The interaction we found in this study between Eps-7D and temperature was not as obvious as to observe the inverse ranking of Eps-7D-late and -early allele at varying temperature, but clear differences in the magnitude of the effect of the Eps-7D allele at different temperature. To the best of our knowledge such interaction had been only recently shown in hexaploid wheat for the Eps-D1 [38], although it had been recognised time ago in diploid wheat [22], and now we expand the concept within commercial wheat germplasm to the new Eps-7D. Both NILs carrying either Eps-7D-late and early accelerated the rate of development when the temperature was increased but the Eps-7D-early had higher sensitivity to temperature than the late allele which made early allele to have much shorter phenology than the late allele under higher temperature. Alleles of Eps genes might confer different optimum temperatures which would be responsible for differences in earliness between lines with the Eps-7D-late and -early allele under various temperatures [37].

\section{Materials and Methods}

The experiments were conducted under controlled conditions in growth chambers (GER-1400 ESP, Radiber SA, Spain) at the University of Lleida, Spain. The pots $\left(200 \mathrm{~cm}^{3}\right)$ were filled with approximately $120-125 \mathrm{~g}$ of mixture of $70 \%$ soil and $30 \%$ peat. Two seeds were sown in each pot at uniform depth $(1 \mathrm{~cm})$ and were kept under dark at room temperature until seedling emergence. Only one seedling was retained per pot before shifting the pots to the growth chamber. Extra pots were sown to select 54 pots per NIL for each chamber which had uniform seedling emergence to avoid even small differences in plant development before the start of the experiment.

Pots were watered once or twice a week based on the growth stage/water requirements/treatment. Micro and macro nutrients were provided through irrigation at 4-leaf stage in all growing conditions. Pots were rotated once a week within each chamber throughout the experimental period to eliminate any spatial variation causing differences in micro-environment.

Treatments consisted of a factorial combination of four near isogenic lines (NILs) differing in the alleles of both Eps-7D (Eps-7D-early and-late) and Ppd-D1 (Ppd-D1a and $P p d-D 1 b)$; two photoperiod conditions and three temperature regimes. The NILs were derived from the cross Paragon and Baj carrying either Eps-7D-late or Eps-7D-early with either $P p d-D 1 a$ or $P p d-D 1 b$ in the background from Baj and Paragon respectively. In this paper we focused on the effects of the Eps-7D gene and all NILs had the insensitive allele for this major $P p d$ gene ( $P p d-D 1 a)$, and in the companion paper [43], we explored the effects of the interaction between Eps-7D and Ppd-D1 (and with temperature). The plants were grown under either 12 or $24 \mathrm{~h}$ photoperiod (short day and long day respectively), the treatment of long day having only half of the lights on so that daily radiation was the same for both photoperiod conditions. Three constant temperature regimes $\left(9,15\right.$ and $\left.18{ }^{\circ} \mathrm{C}\right)$ were imposed under each of the two photoperiods from seedling emergence to anthesis.

Nine randomly chosen plants per NIL in each of the six temperature $\times$ photoperiod conditions were marked at one leaf stage to record the dynamics of leaf appearance until the flag leaf was fully emerged. These plants were arranged in a completely randomised design with 9 replicates. The stage of leaf appearance was recorded three times a week for plants under long day and at least twice a week for plants under short day at all the temperatures following the scale proposed by Haun et al. [71]. The same plants were used to map the fertile florets (number of fertile florets at each spikelet) per spike at anthesis, where florets at least at the green anther stage were considered to be fertile. On all plants we 
measured (i) the phenological stages such as flag leaf emergence (DC39), heading (DC59) and anthesis (DC65) by visual observation following the scale of Zadoks et al. [72]. The dates for each stage were recorded when $50 \%$ of the plants in each NIL and within each temperature $\times$ photoperiod conditions reached that stage.

The rest of the unmarked plants $(45$ in each combination of NIL $\times$ photoperiod $\times$ temperature) were also arranged in a completely randomised design and were sampled at regular intervals (actual frequency depending on temperature and photoperiod treatment) to dissect and record the apex stages of development and number of primordia until the stage of terminal spikelet, and from then to anthesis dissecting particular spikelets to determine the number and stages of each floret primordia. Three plants (replicates) per NIL within each treatment were sampled 2 or 3 times a week (depending on the NIL and treatments). Number of spikelet primordia was calculated a posteriori by subtracting final leaf number from the total number of (leaf and spikelet) primordia recorded until TS. For the determination of stages of development of the spike and florets we used the scale proposed by Waddington et al. [44]. As wheat displays asynchronous development of florets across different spikelets of the spike, the dissection of spikelets to determine the stage of development of individual florets was carried out in three spikelet positions of the spike: apical (the third spikelet from the tip), central (the spikelet in the middle of the spike) or basal spikelets (the third spikelet from the base, or the first fertile spikelet when exceptionally more than three spikelets were infertile at particular samplings). Floret score (dimensionless) was recorded at each sampling for each individual floret developing within each of the three spikelet positions. We only considered for the quantitative analysis of traits determining spike fertility in this paper the floret primordia that reached at least the stage W4.5 (stage when stamen, pistil and carpel primordia are present) as florets failing to reach at least W4.5 hardly reach fertile seed and set seeds [38]. For the dynamics of the number of living florets (floret initiation followed by floret death), again we only took into account florets that at least reached the stage of W4.5 and a floret was considered dead when it did not show developmental progress (advancement in the floret score of the scale of Waddington et al. [44]) in the following consecutive dissections.

For the sake of simplicity, in the results we averaged the floret scores of particular floret positions across all the three spikelets (apical, central and basal). While the development of F1 in all the three spike positions was very similar (smaller error bars) the distal florets (F2 to Fn) had slower development in apical and basal position compared to that of the central spikelet. Thus, most of the variation observed due to Eps-7D or the temperature and photoperiods were mostly visible in florets F2 and F3.

The nine plants per NIL that were reserved for periodically recording the leaf appearance stage were sampled at anthesis, where the final number of fertile florets in each spikelet of the main shoot spike was determined. The florets were numbered F1 to Fn based on their position with respect to rachis, F1 being the most proximal to, and Fn the most distal from, the rachis.

To determine the significance of effects we subjected the data to a full factorial model (a three-way ANOVA) using JMP Pro version 14.0 (SAS Institute Inc., Cary, NC, USA). As the main focus of this paper was to analyse in detail the effect of the Eps-7D gene under each of the six growing conditions, we also carried out one-way ANOVA to determine whether the differences between NILs were significant within each combination of temperature and photoperiod. As the effects of Eps genes are expected to be small, for these analyses we included, in addition to the most conventional levels of probability for significance (i.e., $p<0.05 ; p<0.01 ; p<0.001)$ the $p$-values in each comparison indicating also whenever differences had a $p \leq 0.10$ (i.e., significant at 0.1 probability level) and used $p>0.10$ and $p \gg 0.10$ whenever $0.1>p<0.2$ and $p>0.21$, respectively. 
Supplementary Materials: The following are available online at https:/ / www.mdpi.com/2223-774 7/10/3/547/s1, Figure S1. Relationships between time from seedling emergence to anthesis and its component phases: time from seedling emergence to terminal spikelet (TS, A) and time from then to anthesis, i.e., the late reproductive phase (B) for the both the NILs carrying either Eps-7D-late or early allele under three temperatures and two photoperiod regimes. Figure S2. Relationship between floret development (floret score, a scale proposed by Waddington et al. [44]) and days from seedling emergence for Eps-7D-late (open circles) and early (closed circles) for floret 1 (A,B,E,F,I,J) and floret $4(\mathrm{C}, \mathrm{D}, \mathrm{G}, \mathrm{H}, \mathrm{K}, \mathrm{L})$ under long and shot day at $18(\mathrm{~A}-\mathrm{D}), 15(\mathrm{E}-\mathrm{H})$ and $9{ }^{\circ} \mathrm{C}(\mathrm{I}-\mathrm{L})$. The error bars are standard error of means of floret scores from apical, central and basal spikelets.

Author Contributions: P.A.B.: Investigation, formal analysis, visualization, writing —original draft; R.S.: Supervision, methodology, writing-review and editing; S.B.: methodology, writing-review and editing; S.G.: Conceptualization, funding acquisition, writing-review and editing; G.A.S.: conceptualization, supervision, methodology, visualization, funding acquisition, writing-review and editing. All authors have read and agreed to the published version of the manuscript.

Funding: This research was funded by Spanish Research Agency (AEI), project AGL2015-69595-R; International Wheat Yield Partnership (IWYP), project IWYP25FP.

Data Availability Statement: Data are available upon request from the corresponding authors.

Acknowledgments: We are grateful to the team of laboratory of crop physiology for assisting with laboratory work. PB held a pre-doctoral research contract from the Agency for Management of University and Research (AGAUR) from the Generalitat de Catalunya.

Conflicts of Interest: The authors declare no conflict of interest.

\section{References}

1. Fischer, R.A. Farrer Review. Wheat Physiology: A Review of Recent Developments. Crop Pasture Sci. 2011, 62, 95. [CrossRef]

2. Reynolds, M.P.; Foulkes, J.; Furbank, R.; Griffiths, S.; King, J.; Murchie, E.; Parry, M.; Slafer, G.A. Achieving Yield Gains in Wheat. Plant Cell Environ. 2012, 35, 1799-1823. [CrossRef]

3. Whitechurch, E.M.; Slafer, G.A. Responses to Photoperiod before and after Jointing in Wheat Substitution Lines. Euphytica 2001, 118, 47-51. [CrossRef]

4. González, F.G.; Slafer, G.A.; Miralles, D.J. Floret Development and Survival in Wheat Plants Exposed to Contrasting Photoperiod and Radiation Environments during Stem Elongation. Funct. Plant Biol. 2005, 32, 189-197. [CrossRef] [PubMed]

5. Börner, A.; Worland, A.J.; Plaschke, J.; Schumann, E.; Law, C.N. Pleiotropic Effects of Genes for Reduced Height (Rht) and Day-Length Insensitivity (Ppd) on Yield and Its Components for Wheat Grown in Middle Europe. Plant Breed. 1993, 111, $204-216$. [CrossRef]

6. Foulkes, M.J.; Sylvester-Bradley, R.; Worland, A.J.; Snape, J.W. Effects of a Photoperiod-Response Gene Ppd-D1 on Yield Potential and Drought Resistance in UK Winter Wheat. Euphytica 2004, 135, 63-73. [CrossRef]

7. Gawroński, P.; Ariyadasa, R.; Himmelbach, A.; Poursarebani, N.; Kilian, B.; Stein, N.; Steuernagel, B.; Hensel, G.; Kumlehn, J.; Sehgal, S.K.; et al. A Distorted Circadian Clock Causes Early Flowering and Temperature-Dependent Variation in Spike Development in the Eps-3Am Mutant of Einkorn Wheat. Genetics 2014, 196, 1253-1261. [CrossRef]

8. Lewis, S.; Faricelli, M.E.; Appendino, M.L.; Valárik, M.; Dubcovsky, J. The Chromosome Region Including the Earliness per Se Locus Eps-A M1 Affects the Duration of Early Developmental Phases and Spikelet Number in Diploid Wheat. J. Exp. Bot. 2008, 59, 3595-3607. [CrossRef]

9. Ochagavía, H.; Prieto, P.; Savin, R.; Griffiths, S.; Slafer, G.A. Dynamics of Leaf and Spikelet Primordia Initiation in Wheat as Affected by Ppd-1a Alleles under Field Conditions. J. Exp. Bot. 2018, 69, 2621-2631. [CrossRef]

10. Pérez-Gianmarco, T.I.; Slafer, G.A.; González, F.G. Wheat Pre-Anthesis Development as Affected by Photoperiod Sensitivity Genes (Ppd-1) under Contrasting Photoperiods. Funct. Plant Biol. 2018, 45, 645-657. [CrossRef] [PubMed]

11. Prieto, P.; Ochagavía, H.; Savin, R.; Griffiths, S.; Slafer, G.A. Physiological Determinants of Fertile Floret Survival in Wheat as Affected by Earliness per Se Genes under Field Conditions. Eur. J. Agron. 2018, 99, 206-213. [CrossRef]

12. González, F.G.; Slafer, G.A.; Miralles, D.J. Floret Development and Spike Growth as Affected by Photoperiod during Stem Elongation in Wheat. Field Crops Res. 2003, 81, 29-38. [CrossRef]

13. González, F.G.; Slafer, G.A.; Miralles, D.J. Grain and Floret Number in Response to Photoperiod during Stem Elongation in Fully and Slightly Vernalized Wheats. Field Crops Res. 2003, 81, 17-27. [CrossRef]

14. Serrago, R.A.; Miralles, D.J.; Slafer, G.A. Floret Fertility in Wheat as Affected by Photoperiod during Stem Elongation and Removal of Spikelets at Booting. Eur. J. Agron. 2008, 28, 301-308. [CrossRef]

15. Steinfort, U.; Trevaskis, B.; Fukai, S.; Bell, K.L.; Dreccer, M.F. Vernalisation and Photoperiod Sensitivity in Wheat: Impact on Canopy Development and Yield Components. Field Crops Res. 2017, 201, 108-121. [CrossRef] 
16. Wall, P.C.; Cartwright, P.M. Effects of Photoperiod, Temperature and Vernalization on the Phenology and Spikelet Numbers of Spring Wheats. Ann. Appl. Biol. 1974, 76, 299-309. [CrossRef]

17. Slafer, G.A.; Savin, R.; Sadras, V.O. Coarse and Fine Regulation of Wheat Yield Components in Response to Genotype and Environment. Field Crops Res. 2014, 157, 71-83. [CrossRef]

18. Würschum, T.; Leiser, W.L.; Langer, S.M.; Tucker, M.R.; Longin, C.F.H. Phenotypic and Genetic Analysis of Spike and Kernel Characteristics in Wheat Reveals Long-Term Genetic Trends of Grain Yield Components. Theor. Appl. Genet. 2018, 131, $2071-2084$. [CrossRef]

19. Slafer, G.A. Differences in Phasic Development Rate amongst Wheat Cultivars Independent of Responses to Photoperiod and Vernalization. A Viewpoint of the Intrinsic Earliness Hypothesis. J. Agric. Sci. 1996, 126, 403-419. [CrossRef]

20. Araus, J.L.; Slafer, G.A.; Reynolds, M.P.; Royo, C. Plant Breeding and Drought in C3 Cereals: What Should We Breed For? Ann. Bot. 2002, 89, 925-940. [CrossRef]

21. Richards, R.A. Crop Improvement for Temperate Australia: Future Opportunities. Field Crops Res. 1991, 26, 141-169. [CrossRef]

22. Bullrich, L.; Appendino, M.L.; Tranquilli, G.; Lewis, S.; Dubcovsky, J. Mapping of a Thermo-Sensitive Earliness per Se Gene on Triticum Monococcum Chromosome 1Am. Theor. Appl. Genet. 2002, 105, 585-593. [CrossRef]

23. Griffiths, S.; Simmonds, J.; Leverington, M.; Wang, Y.; Fish, L.; Sayers, L.; Alibert, L.; Orford, S.; Wingen, L.; Herry, L.; et al. Meta-QTL Analysis of the Genetic Control of Ear Emergence in Elite European Winter Wheat Germplasm. Theor. Appl. Genet. 2009, 119, 383-395. [CrossRef] [PubMed]

24. Ochagavía, H.; Prieto, P.; Savin, R.; Griffiths, S.; Slafer, G.A. Earliness per Se Effects on Developmental Traits in Hexaploid Wheat Grown under Field Conditions. Eur. J. Agron. 2018, 99, 214-223. [CrossRef]

25. Zikhali, M.; Leverington-Waite, M.; Fish, L.; Simmonds, J.; Orford, S.; Wingen, L.U.; Goram, R.; Gosman, N.; Bentley, A.; Griffiths, S. Validation of a 1DL Earliness per Se (Eps) Flowering QTL in Bread Wheat (Triticum Aestivum). Mol. Breed. 2014, 34, 1023-1033. [CrossRef] [PubMed]

26. Alvarez, M.A.; Tranquilli, G.; Lewis, S.; Kippes, N.; Dubcovsky, J. Genetic and Physical Mapping of the Earliness per Se Locus Eps-A m 1 in Triticum Monococcum Identifies EARLY FLOWERING 3 (ELF3) as a Candidate Gene. Funct. Integr. Genomics 2016, 16, 365-382. [CrossRef]

27. Fischer, R.A. Understanding the Physiological Basis of Yield Potential in Wheat. J. Agric. Sci. 2007, 145, 99-113. [CrossRef]

28. Slafer, G.A. Genetic Basis of Yield as Viewed from a Crop Physiologist's Perspective. Ann. Appl. Biol. 2003, 142, 117-128. [CrossRef]

29. Halloran, G.M.; Pennell, A.L. Duration and Rate of Development Phases in Wheat in Two Environments. Ann. Bot. 1982, 49, 115-121. [CrossRef]

30. Abbate, P.E.; Andrade, F.H.; Culot, J.P.; Bindraban, P.S. Grain Yield in Wheat: Effects of Radiation during Spike Growth Period. Field Crops Res. 1997, 54, 245-257. [CrossRef]

31. Ferrante, A.; Savin, R.; Slafer, G.A. Is Floret Primordia Death Triggered by Floret Development in Durum Wheat? J. Exp. Bot. 2013, 64, 2859-2869. [CrossRef] [PubMed]

32. González, F.G.; Slafer, G.A.; Miralles, D.J. Pre-Anthesis Development and Number of Fertile Florets in Wheat as Affected by Photoperiod Sensitivity Genes Ppd-D1 and Ppd-B1. Euphytica 2005, 146, 253-269. [CrossRef]

33. Miralles, D.J.; Richards, R.A. Responses of Leaf and Tiller Emergence and Primordium Initiation in Wheat and Barley to Interchanged Photoperiod. Ann. Bot. 2000, 85, 655-663. [CrossRef]

34. Prieto, P.; Ochagavía, H.; Savin, R.; Griffiths, S.; Slafer, G.A. Dynamics of Floret Initiation/Death Determining Spike Fertility in Wheat as Affected by Ppd Genes under Field Conditions. J. Exp. Bot. 2018, 69, 2633-2645. [CrossRef]

35. Snape, J.W.; Butterworth, K.; Whitechurch, E.; Worland, A.J. Waiting for Fine Times: Genetics of Flowering Time in Wheat. Euphytica 2001, 119, 185-190. [CrossRef]

36. Slafer, G.A.; Rawson, H.M. Intrinsic Earliness and Basic Development Rate Assessed for Their Response to Temperature in Wheat. Euphytica 1995, 83, 175-183. [CrossRef]

37. Appendino, M.L.; Slafer, G.A. Earliness per Se and Its Dependence upon Temperature in Diploid Wheat Lines Differing in the Major Gene Eps-Am1 Alleles. J. Agric. Sci. 2003, 141, 149-154. [CrossRef]

38. Ochagavía, H.; Prieto, P.; Zikhali, M.; Griffiths, S.; Slafer, G.A. Earliness Per Se by Temperature Interaction on Wheat Development. Sci. Rep. 2019, 9, 2584. [CrossRef]

39. Prieto, P.; Ochagavía, H.; Griffiths, S.; Slafer, G.A. Earliness per Se×temperature Interaction: Consequences on Leaf, Spikelet, and Floret Development in Wheat. J. Exp. Bot. 2020, 71, 1956-1968. [CrossRef]

40. Basavaraddi, P.A.; Savin, R.; Wingen, L.U.; Bencivenga, S.; Przewieslik-Allen, A.M.; Griffiths, S.; Slafer, G.A. Interactions between Two QTLs for Time to Anthesis on Spike Development and Fertility in Wheat. Sci. Rep. 2021, 11, 2451. [CrossRef]

41. Wingen, L.U.; West, C.; Waite, M.L.; Collier, S.; Orford, S.; Goram, R.; Yang, C.Y.; King, J.; Allen, A.M.; Burridge, A.; et al. Wheat Landrace Genome Diversity. Genetics 2017, 205, 1657-1676. [CrossRef]

42. Mondal, S.; Singh, R.P.; Mason, E.R.; Huerta-Espino, J.; Autrique, E.; Joshi, A.K. Grain Yield, Adaptation and Progress in Breeding for Early-Maturing and Heat-Tolerant Wheat Lines in South Asia. Field Crops Res. 2016, 192, 78-85. [CrossRef] [PubMed]

43. Basavaraddi, P.A.; Savin, R.; Bencivenga, S.; Griffiths, S.; Slafer, G.A. Phenology and Floret Development as Affected by the Interaction between Eps-7D and Ppd-D1. Plants 2021, 10, 533. [CrossRef] 
44. Waddington, S.R.; Cartwright, P.M.; Wall, P.C. A Quantitative Scale of Spike Initial and Pistil Development in Barley and Wheat. Ann. Bot. 1983, 51, 119-130. [CrossRef]

45. Slafer, G.A.; Rawson, H.M. Sensitivity of Wheat Phasic Development to Major Environmental Factors: A Re-Examination of Some Assumptions Made by Physiologists and Modellers. Aust. J. Plant Physiol. 1994, 21, 393-426. [CrossRef]

46. John, R.P.; Megan, G. Temperatures and the Growth and Development of Wheat: A Review. Eur. J. Agron. 1999, $10,23-36$.

47. Parent, B.; Tardieu, F. Temperature Responses of Developmental Processes Have Not Been Affected by Breeding in Different Ecological Areas for 17 Crop Species. New Phytol. 2012, 194, 760-774. [CrossRef] [PubMed]

48. Gillooly, J.F.; Charnov, E.L.; West, G.B.; Savage, V.M.; Brown, J.H. Effect of Size and Temperature on Developmental Time. Nature 2002, 417, 70-73. [CrossRef]

49. Slafer, G.A.; Rawson, H.M. Phyllochron in Wheat as Affected by Photoperiod under Two Temperature Regimes. Aust. J. Plant Physiol. 1997, 24, 151-158. [CrossRef]

50. Ochagavía, H.; Prieto, P.; Savin, R.; Griffiths, S.; Slafer, G.A. Duration of Developmental Phases, and Dynamics of Leaf Appearance and Tillering, as Affected by Source and Doses of Photoperiod Insensitivity Alleles in Wheat under Field Conditions. Field Crops Res. 2017, 214, 45-55. [CrossRef]

51. Miglietta, F. Effect of Photoperiod and Temperature on Leaf Initiation Rates in Wheat (Triticum Spp.). Field Crops Res. 1989, 21, 121-130. [CrossRef]

52. Langer, S.M.; Longin, C.F.H.; Würschum, T. Flowering Time Control in European Winter Wheat. Front. Plant Sci. 2014,5 , 537. [CrossRef]

53. Bentley, A.R.; Turner, A.S.; Gosman, N.; Leigh, F.J.; Maccaferri, M.; Dreisigacker, S.; Greenland, A.; Laurie, D.A. Frequency of Photoperiod-Insensitive Ppd-A1a Alleles in Tetraploid, Hexaploid and Synthetic Hexaploid Wheat Germplasm. Plant Breed. 2011, 130, 10-15. [CrossRef]

54. Shaw, L.M.; Turner, A.S.; Laurie, D.A. The Impact of Photoperiod Insensitive Ppd-1a Mutations on the Photoperiod Pathway across the Three Genomes of Hexaploid Wheat (Triticum Aestivum). Plant J. 2012, 71, 71-81. [CrossRef] [PubMed]

55. Shaw, L.M.; Turner, A.S.; Herry, L.; Griffiths, S.; Laurie, D.A. Mutant Alleles of Photoperiod-1 in Wheat (Triticum Aestivum L.) That Confer a Late Flowering Phenotype in Long Days. PLoS ONE 2013, 8, e79459. [CrossRef] [PubMed]

56. Slafer, G.A.; Rawson, H.M. Does Temperature Affect Final Numbers of Primordia in Wheat? Field Crops Res. 1994, 39, 111-117. [CrossRef]

57. Mosaad, M.G.; Ortiz-Ferrara, G.; Mahalakshmi, V.; Fischer, R.A. Phyllochron Response to Vernalization and Photoperiod in Spring Wheat. Crop Sci. 1995, 35, 168-171. [CrossRef]

58. Rahman, M.S.; Wilson, J.H. Determination of Spikelet Number in Wheat. III.* Effect of Varying Temperature on Ear Development. Aust. J. Agric. Res. 1978, 29, 459-467. [CrossRef]

59. Slafer, G.A.; Savin, R. Developmental Base Temperature in Different Phenological Phases of Wheat (Triticum Aestivum). J. Exp. Bot. 1991, 42, 1077-1082. [CrossRef]

60. Kiss, T.; Dixon, L.E.; Soltész, A.; Bányai, J.; Mayer, M.; Balla, K.; Allard, V.; Galiba, G.; Slafer, G.A.; Griffiths, S.; et al. Effects of Ambient Temperature in Association with Photoperiod on Phenology and on the Expressions of Major Plant Developmental Genes in Wheat (Triticum Aestivum L.). Plant Cell Environ. 2017, 40, 1629-1642. [CrossRef]

61. Slafer, G.A.; Rawson, H.M. Responses to Photoperiod Change with Phenophase and Temperature during Wheat Development. Field Crops Res. 1996, 46, 1-13. [CrossRef]

62. Hemming, M.N.; Walford, S.A.; Fieg, S.; Dennis, E.S.; Trevaskis, B. Identification of High-Temperature-Responsive Genes in Cereals. Plant Physiol. 2012, 158, 1439-1450. [CrossRef] [PubMed]

63. Karsai, I.; Igartua, E.; Casas, A.M.; Kiss, T.; Soós, V.; Balla, K.; Bedo, Z.; Veisz, O. Developmental Patterns of a Large Set of Barley (Hordeum Vulgare) Cultivars in Response to Ambient Temperature. Ann. Appl. Biol. 2013, 162, 309-323. [CrossRef]

64. González-Navarro, O.E.; Griffiths, S.; Molero, G.; Reynolds, M.P.; Slafer, G.A. Dynamics of Floret Development Determining Differences in Spike Fertility in an Elite Population of Wheat. Field Crops Res. 2015, 172, 21-31. [CrossRef]

65. Slafer, G.A.; Elia, M.; Savin, R.; García, G.A.; Terrile, I.I.; Ferrante, A.; Miralles, D.J.; González, F.G. Fruiting Efficiency: An Alternative Trait to Further Rise Wheat Yield. Food Energy Secur. 2015, 4, 92-109. [CrossRef]

66. Prasad, P.V.V.; Bheemanahalli, R.; Jagadish, S.V.K. Field crops and the fear of heat stress-opportunities: Challenges and future directions. Field Crops Res. 2017, 200, 114-121. [CrossRef]

67. Slafer, G.A.; Savin, R. Can N management affect the magnitude of yield loss due to heat waves in wheat and maize? Curr. Opin. Plant Biol. 2018, 45, 276-283. [CrossRef]

68. Makowski, D.; Marajo-Petitzon, E.; Durand, J.-L.; Ben-Ari, T. Quantitative synthesis of temperature, $\mathrm{CO}_{2}$, rainfall, and adaptation effects on global crop yields. Eur. J. Agron. 2020, 115, 126041. [CrossRef]

69. Atkinson, D.; Porter, J.R. Temperature, Plant Development and Crop Yields. Trends Plant Sci. 1996, 1, 119-124. [CrossRef]

70. Rawson, H.M.; Richards, R.A. Effects of High Temperature and Photoperiod on Floral Development in Wheat Isolines Differing in Vernalisation and Photoperiod Genes. Field Crops Res. 1993, 32, 181-192. [CrossRef]

71. Haun, J.R. Visual Quantification of Wheat Development. Agron. J. 1973, 65, 116-119. [CrossRef]

72. Zadoks, J.C.; Chang, T.T.; Konzak, C.F. A Decimal Code for the Growth Stages of Cereals. Weed Res. 1974, 14, 415-421. [CrossRef] 